\title{
The Neuropeptide Oxytocin Induces a Social Altruism Bias
}

\author{
Nina Marsh, ${ }^{1,3}$ ○Dirk Scheele, ${ }^{1,3}$ - Holger Gerhardt, ${ }^{4}$ Sabrina Strang, ${ }^{5}$ Laura Enax, ${ }^{2,4,7}$ Bernd Weber, $, 2,4$ \\ Wolfgang Maier, ${ }^{1,6}$ and ${ }^{-D e n e ́ ~ H u r l e m a n n ~}{ }^{1,3}$ \\ Departments of ${ }^{1}$ Psychiatry and ${ }^{2}$ Epileptology and ${ }^{3}$ Division of Medical Psychology, University of Bonn Medical Center, 53105 Bonn, Germany, ${ }^{4}$ Center for \\ Economics and Neuroscience, University of Bonn, 53127 Bonn, Germany, ${ }^{5}$ Department of Psychology, University of Lübeck, 23562 Lübeck, Germany, \\ ${ }^{6}$ German Center of Neurodegenerative Diseases (DZNE), Helmholtz Association, 53175 Bonn, Germany, and 7Department of NeuroCognition/Imaging, Life \\ and Brain Center, 53127 Bonn, Germany
}

Current psychological concepts of social and ecological responsibility emphasize the relevance of altruism, suggesting that more altruistic individuals are more likely to engage in sustainable behaviors. Emerging evidence indicates a central role of the neuropeptide oxytocin in promoting altruism. Whether this influence extends to ecological responsibility or is limited to the social domain remains unknown. In two independent experiments involving 172 human participants, we addressed this question by exposing subjects to a sustainability-related monetary donation task, with the option to support either socially or ecologically framed charities. We found that oxytocin induced a context-dependent change in altruistic behavior away from pro-environmental toward pro-social donations, while keeping constant the overall proportion of donated money. This pro-social bias transcended to the domain of sustainable consumption. Collectively, our findings demonstrate that altruistic priorities vary as a function of oxytocin system activity, which has implications for the promotion of pro-environmental attitudes and eco-friendly behaviors.

Key words: altruism; decision-making; oxytocin; sustainability

\section{Significance Statement}

Individual responses to ecological and social sustainability require a shift in personal priorities away from selfish to more altruistic behaviors. Emerging evidence indicates a central role of the hypothalamic peptide oxytocin in promoting altruism, but whether the influence of oxytocin benefits altruistic decision-making in the context of ecological and social sustainability is unclear. In two independent behavioral experiments involving 172 human subjects, we show that heightened oxytocin system activity induces a social altruism bias at the cost of ecological responsibility. Our results have fundamental implications for policy interventions and business strategies designed to sustain ecological resources by suggesting that a social framing may attract more individuals to engage in pro-environmental and eco-friendly behaviors.

\section{Introduction}

Sustainable development of society and eco-systems is crucial for human welfare today and in the future (Arrow and Levin, 2009; Hauser et al., 2014). To motivate more individuals to act responsibly with regard to social prosperity and environmental protec-

Received Aug. 25, 2015; revised 0ct. 8, 2015; accepted 0ct. 14, 2015.

Author contributions: N.M., D.S., and R.H. designed research; N.M., H.G., S.S., and L.E. performed research; N.M., D.S., and R.H. analyzed data; N.M., D.S., B.W., W.M., and R.H. wrote the paper.

This work was supported by a German Research Foundation (Deutsche Forschungsgemeinschaft, DFG) Grant (HU 1202/4-1 and BE 5465/2-1 to R.H. and D.S.). B.W. was supported by a Heisenberg Grant provided by the DFG (We 4427/3-2). L.E. was supported by the Bundesministerium für Bildung und Forschung-funded Competence Cluster DietBB (01EA1410A). We thank two anonymous reviewers for their valuable comments.

The authors declare no competing financial interests.

Correspondence should be addressed to Dr. René Hurlemann, Associate Professor, Department of Psychiatry and Division of Medical Psychology, University of Bonn Medical Center, 53105 Bonn, Germany. E-mail: renehurlemann@icloud.com.

DOI:10.1523/JNEUROSCI.3199-15.2015

Copyright $\odot 2015$ the authors $\quad 0270-6474 / 15 / 3515696-06 \$ 15.00 / 0$ tion, a transdisciplinary approach aiming to understand the neurobiology of sustainable decision-making is required.

From a behavioral perspective, sustainable decisions pose a challenge to each individual, as ecological and social responsibility require a shift in personal priorities away from selfish toward more altruistic goals (Nowak and Sigmund, 2005; Evans et al., 2013).

Altruism can be classified as pro-environmental when directed toward ecological responsibility, including climate change prevention and the preservation of biodiversity, or pro-social when focusing on social responsibility, including poverty reduction and humanitarian aid in developing countries and war zones (World Commission on Environment and Development, 1987; Thompson and Barton, 1994). Drawing on the adoption process of the post-2015 Development Agenda of the United Nations, this differentiation would be particularly informative in the light of new experimental evidence showing that pro-environmental and pro-social altruism are in fact distinct in the brain mechanisms that support them. 
Table 1. Demographics, personality traits and a priori effects on pro-social and pro-environmental behavior (Experiments 2A and 2B)

\begin{tabular}{|c|c|c|c|c|c|c|c|c|}
\hline & \multicolumn{4}{|l|}{ Ecological frame } & \multicolumn{4}{|l|}{ Social frame } \\
\hline & $\begin{array}{l}\mathrm{OXT}^{\mathrm{IN}} \text { group }(n=26) \\
\text { Mean (SD) }\end{array}$ & $\begin{array}{l}\mathrm{PLC}{ }^{\mathrm{IN}} \text { group }(n=26) \\
\text { Mean (SD) }\end{array}$ & $t$ & $p$ & $\begin{array}{l}\text { OXT group }(n=24) \\
\text { Mean }(S D)\end{array}$ & $\begin{array}{l}\text { PLC group }(n=24) \\
\text { Mean }(S D)\end{array}$ & $t$ & $p$ \\
\hline Education (years) & $16.22(1.90)$ & $16.08(2.03)$ & 0.23 & 0.81 & $16.37(2.18)$ & $15.68(1.55)$ & 1.22 & 0.23 \\
\hline Donations $€ /$ year (pro-social) & $13.30(49.70)$ & $6.29(15.73)$ & 0.68 & 0.49 & $11.70(29.69)$ & $14.95(30.91)$ & -0.37 & 0.71 \\
\hline Donations $€ /$ year (pro-environmental) & $3.07(8.95)$ & $7.75(22.82)$ & -0.93 & 0.33 & $4.37(12.45)$ & $9.50(22.23)$ & -0.98 & 0.33 \\
\hline Social responsibility ${ }^{a}$ & $4.69(0.88)$ & $5.08(0.77)$ & -1.66 & 0.10 & $4.70(1.08)$ & $4.79(1.28)$ & -0.24 & 0.80 \\
\hline Autism-Spectrum Quotient & $14.25(5.11)$ & $13.57(3.89)$ & 0.52 & 0.60 & $14.33(6.99)$ & $17.66(5.28)$ & -1.86 & 0.07 \\
\hline State-Trait Anxiety Inventory & $34.00(6.99)$ & $33.73(5.96)$ & 0.14 & 0.88 & $33.45(7.02)$ & $33.70(7.33)$ & -0.12 & 0.90 \\
\hline Beck Depression Inventory & $4.62(3.54)$ & $4.21(4.11)$ & 0.37 & 0.71 & $3.58(3.57)$ & $4.29(3.25)$ & -0.71 & 0.47 \\
\hline
\end{tabular}

${ }^{a}$ Social responsibility attitudes were assessed using a 6-item questionnaire asking participants about attitudes and beliefs towards pro-social behavior (maximum possible score $=8$ ).

${ }^{b}$ Environmental responsibility attitudes were assessed using a 5 -item questionnaire asking participants about attitudes and beliefs towards pro-environmental behavior (maximum possible score $=8$ ).

Current perspectives on the neurobiological substrates of (parochial) altruism emphasize a central role of the hypothalamic peptide oxytocin (OXT; De Dreu et al., 2010; Barraza et al., 2011; Cardoso et al., 2012; Huffmeijer et al., 2012; Rilling et al., 2012; Declerck et al., 2014). Whether the influence of OXT on altruism induces a bias toward pro-social behavior, perhaps at the cost of ecological responsibility, is unclear. In two independent behavioral experiments involving a total of 172 participants, we specifically addressed this question. The rationale of Experiment 1 was to measure endogenous OXT concentrations in saliva sampled from 73 male and female subjects exposed to a double-blind sustainability-related donation task, with the option to support either socially or ecologically framed charities with a maximum possible donation of $€ 10$. In Experiment $2 \mathrm{~A}$, an independent sample of 100 male subjects was tested on the same behavioral task after receiving a 24-IU nasal dose of synthetic OXT $\left(\mathrm{OXT}^{\mathrm{IN}}\right)$ or placebo $\left(\mathrm{PLC}^{\mathrm{IN}}\right)$. We hypothesized that higher endogenous OXT concentrations as well as exogenous delivery of $\mathrm{OXT}^{\mathrm{IN}}$ would be associated with a larger prevalence of pro-social donations, suggesting that OXT is crucial for enhancing social responsibility and facilitating sustainable behaviors related to it. To further test this prediction, subjects performed a second task, in which they had to decide for a variety of food and clothing products whether they would purchase a conventionally manufactured version at an average market price or a sustainable version, with the additional instruction to indicate how much money they would be willing to spend for it (Experiment 2B).

\section{Materials and Methods}

Our study was approved by the Institutional Review Board of the Faculty of Medicine of the University of Bonn and performed in compliance with the latest revision of the Declaration of Helsinki.

Experiment 1. In Experiment 1, a total of 73 healthy female $(n=44)$ and male $(n=29)$ subjects (mean age \pm SD, $22.31 \pm 3.2$ years) were enrolled after giving written, informed consent. Because one subject did not complete the donation task, the final sample consisted of 72 participants. Saliva samples for measuring endogenous OXT concentrations were taken before participants were randomly assigned to either an ecologically $(n=41)$ or socially $(n=32)$ framed version of the donation task. This contextual framing was achieved using highly standardized instructions that differed in terms of social versus ecological content, but were identical regarding formal criteria such as style, word count, and formatting. By instruction, participants assigned to the ecological frame were primed toward pro-environmental altruism by emphasizing that their donation would preserve a rainforest area in the Congo Delta. In contrast, participants assigned to the social frame were primed toward pro-social altruism by emphasizing that their donation would preserve indigenous people living in that area. Together with the instruction form, participants received an envelope containing ten $€ 1$ coins. In both experimental frames, participants had the option to anonymously donate some, none, or all of their money to the charity. Envelopes containing the donations from each participant were collected in a neutral box placed in the testing room. In addition, participants had to write down the amount of their donation on the instruction form. All forms were later collected by a blinded experimenter. Given that this experiment took place in a lecture hall, peer-group engagement could have provided an incentive for cheating (Gino et al., 2009). Thus, before the experiment, each envelope and the corresponding instruction form were prepared with a hidden code, thus allowing us to control for cheating without revealing the participant's identity (Gino et al., 2010). To determine a potential relationship between endogenous OXT concentrations at baseline and subsequent task-related behavior, saliva samples were collected with commercial sampling devices (Salivettes, Sarstedt). Salivettes were immediately centrifuged at $4180 \times g$ for 2 min and aliquoted samples were stored at $-80^{\circ} \mathrm{C}$ until assayed. Saliva OXT was extracted and quantified by a highly sensitive and specific radioimmunoassay (RIAgnosis). The limit of detection was $0.1-0.5 \mathrm{pg}$ depending on the age of the tracer. Intra-assay and interassay coefficients of variability were $<10 \%$. All samples to be compared were assayed in the same batch, i.e., under intraassay conditions (Striepens et al., 2013).

Experiment 2. In Experiment 2, potential volunteers were invited to sign up for participation via the online database "hroot" (Bock et al., 2014) of the BonnEconLab. A total of 113 healthy male participants were enrolled after giving written informed consent. We used a double-blind, randomized, parallel-group trial design and administered a 24-IU nasal dose of either OXT $^{\mathrm{IN}}$ or PLC ${ }^{\mathrm{IN}}$, both provided by Sigma-Tau Pharmaceuticals. The placebo solution contained the identical ingredients except the peptide itself. The experiment comprised an initial screening session followed by the test session $3 \mathrm{~d}$ apart. Screening entailed the exclusion of current or past physical or psychiatric illness (including drug and alcohol abuse) as assessed by medical history and the Mini-International Neuropsychiatric Interview (Sheehan et al., 1998). Furthermore, we evaluated cognitive performance as well as social and ecological attitudes. To control for possible pretreatment differences, we assessed anxiety traits with the State-Trait Anxiety Inventory (Spielberger, 1984), depressive symptoms with the Beck Depression Inventory (Beck et al., 1961), early social adversity with the Childhood Trauma Questionnaire (Bernstein and Fink, 1998), and autistic-like traits with the Autism Spectrum Quotient (Baron-Cohen et al., 2001). Furthermore, participants were assessed on their pro-social and pro-environmental attitudes based on self-report inventories (Rushton et al., 1981; National Geographic, 2014). In addition, they were asked to indicate their personal income and donation behavior during the past year. There were no a priori differences between the OXT ${ }^{\mathrm{IN}}$ and PLC ${ }^{\mathrm{IN}}$ groups on these factors in the ecological frame nor in the social frame (Table 1). Moreover, subjects were naive to prescription-strength psychoactive medication and had not taken any over-the-counter psychoactive medication in the preceding 4 weeks. Subjects were asked to maintain their regular sleep and waking times and 
to abstain from caffeine and alcohol intake on the day of the test session. During testing, 13 subjects did not complete the donation task and had to be excluded from analysis, such that the final sample consisted of 100 subjects (mean age $\pm \mathrm{SD}, 23.02 \pm 2.6$ years). Of these, 48 subjects had been assigned to the social frame and 52 subjects to the ecological frame. To diminish social desirability effects, each participant was seated alone in a separate test cubicle closed off with curtains. This experimental setting eliminated any interactions with peers or the experimenter, thus decreasing possible social concerns for cheating (Mazar et al., 2008). In Experiment 2A, subjects were exposed to the same sustainability-related donation task and instructional primes as established in Experiment 1. In Experiment 2B, participants were tested on their willingness to pay for sustainable versus non-sustainable consumption goods. By instruction, sustainable goods were framed along social criteria as suggested by Fairtrade (http://www.fairtrade. net/our-vision.html), with specific emphasis on improving labor conditions and poverty, or ecological criteria as inspired by Rainforest Alliance (http://www.rainforest-alliance. org/about), with specific emphasis on conserving biodiversity. Participants were presented with a catalog showing color pictures and category labels of 15 different food and clothing products and had to decide for each of these items whether they would purchase the conventionally manufactured version at an average market price or the sustainable version, with the additional instruction to indicate the exact sum they would be willing to pay for it. Brand names were removed from all images to avoid a confounding influence of individual preferences.

Statistical analysis. Demographic, neuropsychological, and behavioral data were analyzed using IBM SPSS Statistics 21. Quantitative behavioral data were compared using dependent $t$ tests, and Pearson's product-moment correlation was used for correlation analysis. Etasquared and Cohen's $d$ were calculated as measures of effect size. For qualitative variables, Pearson's $\chi^{2}$ tests were used. All reported $p$ values are two-tailed if not otherwise stated, and $p$ values of $p<0.05$ were considered significant. Wilson score intervals with continuity correction were used to compute confidence intervals (CIs) for proportions.

\section{Results}

In Experiment $1(n=72)$, the overall amount of money each participant donated did not differ between the ecological $(€ 6.61 \pm 4.09)$ and social (€7.17 \pm $3.61)$ frames $(p=0.53)$. However, we detected a correlation between the donation amount and endogenous OXT concentrations specifically for the social frame $(r=$ $0.45, p=0.01)$, but not for the ecological frame $(r=0.19, p=$ 0.23 ). Based on the donated sums, the sample was mediandichotomized, resulting in a subsample of maximum altruists $(n=37 ; 51 \%)$ who donated all of their money $(€ 10)$ and another

A

A (i) Salivary oxytocin concentration and donations

(i) Effects of intranasal oxytocin on donations
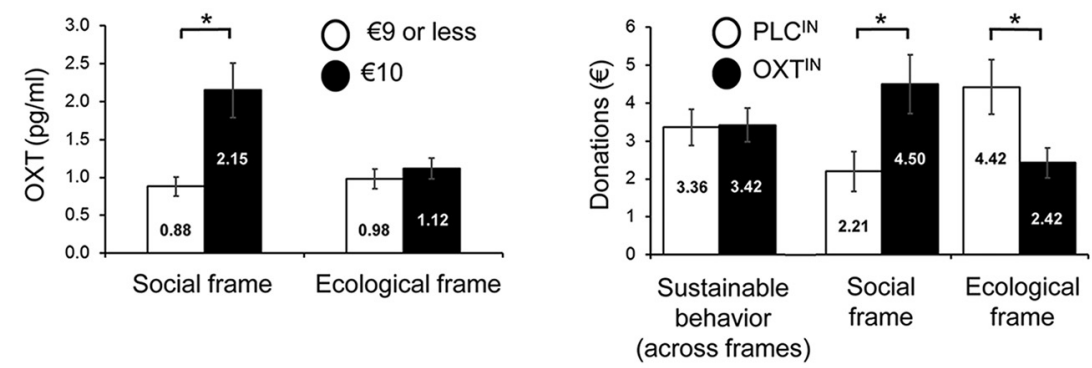

(ii) Donation distribution in the social frame

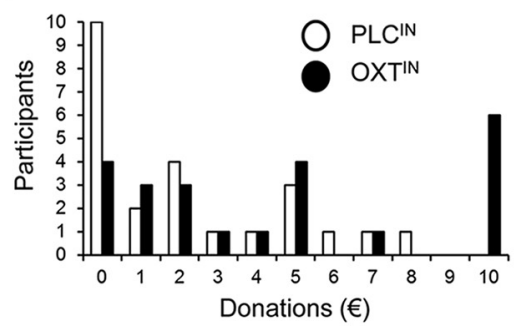

(iii) Donation distribution in the ecological frame

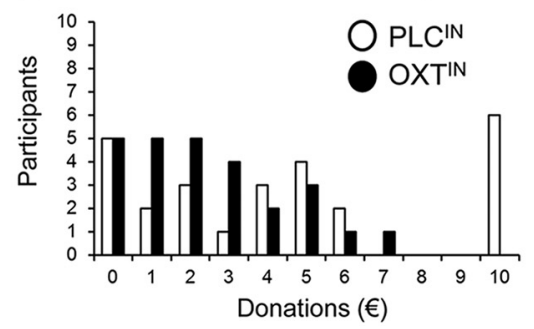

Figure 1. Results obtained with the sustainability-related donation task. A, Salivary OXT concentration and donations (Experiment 1). In the social frame $(n=32)$, participants who donated all of their money exhibited significantly higher endogenous OXT concentrations compared with participants who donated $€ 9$ or less. $B$, Effects of OXT ${ }^{1 \mathrm{~N}}$ on the donated amounts and the distribution profiles of donations (Experiment $2 \mathrm{~A}$ ). $\boldsymbol{i}, 0 \times \mathrm{XT}^{\mathrm{N}}$ more than doubled the sums donated in the social frame and substantially decreased donations in the ecological frame, while keeping constant the overall proportion of donated money to a charity. also tended to increase the number of participants who were willing to donate at least $€ 1$ to the social charity (83.33\%) compared with $\operatorname{PLC}{ }^{\mathbb{N}}(58.3 \%)$. iii, In the ecological frame, the proportions of participants who donated at least $€ 1$ were identical in the PLC ${ }^{\mathbb{N}}$ $(80.77 \%)$ and $0 X T^{\text {IN }}$ group (80.77\%). Error bars indicate the SEM. ${ }^{*} p<0.05$.

(i) Sustainable food products

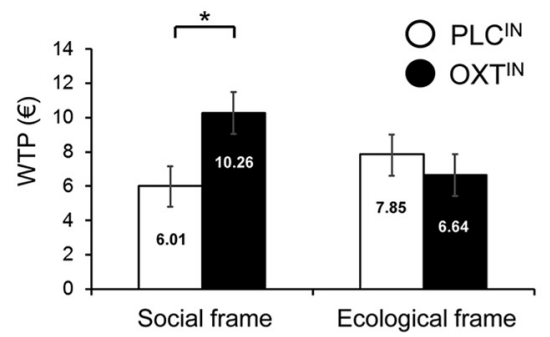

B

(i) Sustainable food products

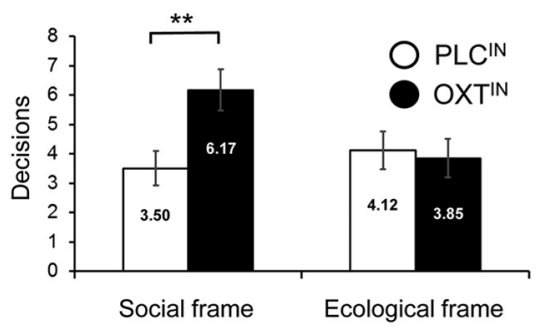

(ii) Sustainable clothing products

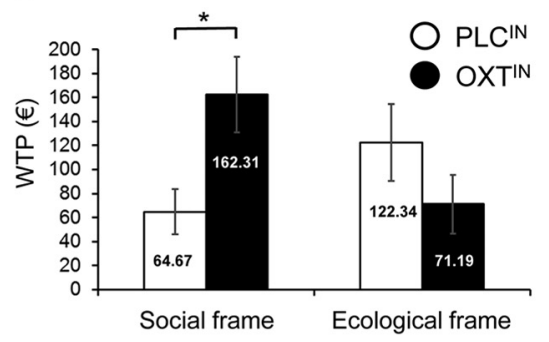

(ii) Sustainable clothing products

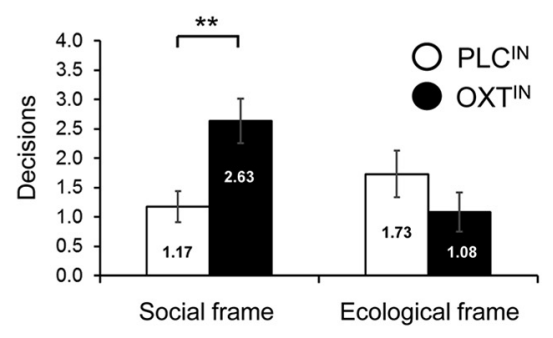

Figure 2. Effects of $0 \mathrm{XT}^{\mathrm{IN}}$ on the willingness to pay (WTP) and decisions for sustainable consumption products (Experiment 2B). $A, 0 X T^{1 N}$ nearly doubled the amount of money participants were willing to pay for socially sustainable food products $(\boldsymbol{i})$ and more than doubled the amount of money devoted to socially sustainable clothing products (ii). B, Under OXT ${ }^{\mathrm{IN}}$, the majority of food (i) and clothing (ii) products chosen by the participants were socially sustainable. ${ }^{*} p<0.05$, ${ }^{* *} p<0.01$.

subsample of participants who donated $€ 9$ or less $(n=35 ; 49 \%)$. A univariate ANOVA with the between-subject factors "frame" (pro-social, pro-environmental) and "donations" (€10, €9 or less) and the endogenous OXT concentrations as dependent vari- 
able yielded main effects of frame $\left(F_{(1,68)}=4.97, p=0.03, \eta^{2}=\right.$ $0.07)$ and donations $\left(F_{(1,68)}=11.23, p<0.01, \eta^{2}=0.14\right)$ as well as an interaction of frame and donations $\left(F_{(1,68)}=7.31, p<0.01\right.$, $\left.\eta^{2}=0.10\right)$. Interestingly, maximum altruism was associated with higher endogenous OXT concentrations in the social frame only (Fig. 1A), suggesting a mechanistic link between socially responsible behavior on the one hand and endogenous OXT system activity on the other.

In Experiment 2A, participants $(n=100)$ decided to keep two-thirds of the $€ 10$ endowment for themselves and donate onethird regardless of treatment; i.e., OXT ${ }^{\mathrm{IN}}$ neither altered altruistic attitude in general nor did it provoke "irrational" donations. However, a repeated-measures ANOVA with the betweensubject factors "treatment" (OXT ${ }^{\mathrm{IN}}, \mathrm{PLC}^{\mathrm{IN}}$ ) and "frame" (prosocial, pro-environmental) and the dependent variable "donation" yielded a highly significant interaction effect of treatment and frame $\left(F_{(1,96)}=12.09, p<0.01, \eta^{2}=0.11\right)$. Post hoc $t$ tests revealed that OXT ${ }^{\mathrm{IN}}$ more than doubled $(+104 \%)$ the sums donated in the social frame (OXT ${ }^{\mathrm{IN}}: € 4.50 \pm 3.78$; PLC: $€ 2.21 \pm$ $\left.2.55 ; t_{(40.40)}=2.46, p=0.02, d=0.73\right)$, whereas it nearly halved $(-45 \%)$ the sums donated in the ecological frame $\left(\mathrm{OXT}^{\mathrm{IN}}\right.$ : $€ 2.42 \pm 2.00 ; \mathrm{PLC}^{\mathrm{IN}}: € 4.42 \pm 3.66 ; t_{(38.77)}=-2.45, p=0.02, d=$ $-0.69)$, suggesting that $\mathrm{OXT}^{\mathrm{IN}}$ induced an altruistic bias toward pro-social decisions at the cost of ecological responsibility (Fig. $1 B$ ). The interaction of treatment and frame remained significant even when we restricted our analysis to participants donating at least $€ 1\left(F_{(1,72)}=9.68, p<0.01, \eta^{2}=0.12\right)$. Treatment with $\mathrm{OXT}^{\mathrm{IN}}$ not only had the effect that the sums donated in the social frame raised by a factor 2, but it also tended to increase the prevalence of altruistic behavior: under $\mathrm{OXT}^{\mathrm{IN}}$, more participants were willing to donate at least $€ 1$ to the social charity (83.33\%; 95\% CI $[61.81,94.52])$ compared with PLC ${ }^{\mathrm{IN}}(58.3 \%$, 95\% CI $[36.94,77.20])$. The smallness of the overlap in CIs suggests that the observed difference was reliable. In the ecological frame, the proportions of participants who donated at least $€ 1$ were identical in the $\operatorname{PLC}^{\mathrm{IN}}(80.77 \%, 95 \%$ CI $[60.02,92.69])$ and $\mathrm{OXT}^{\mathrm{IN}}$ groups (80.77\%, 95\% CI [60.02, 92.69]; Fig. 1B).

Intriguingly, a similar pattern of results emerged in Experiment $2 \mathrm{~B}$, evident in an interaction effect of treatment and frame both for the food category (number of products: $F_{(1,96)}=5.15$, $p=0.03, \eta^{2}=0.05$; sums devoted to products: $F_{(1,94)}=5.16, p=$ $0.03, \eta^{2}=0.05$ ) and for the clothing category (number of products: $F_{(1,95)}=9.14, p<0.01, \eta^{2}=0.09$; sums devoted to products: $\left.F_{(1,96)}=7.38, p<0.01, \eta^{2}=0.07\right)$. This interaction is driven by larger effects of OXT ${ }^{\mathrm{IN}}$ in the social frame than in the ecological frame (Fig. 2A,B). Post hoc $t$ tests restricted to the social frame confirmed that under OXT ${ }^{\mathrm{IN}}$, the majority of food products $\left(\mathrm{OXT}^{\mathrm{IN}}, 62 \%\right.$; $\mathrm{PLC}^{\mathrm{IN}}, 35 \% ; t_{(46)}=2.90, p<0.01, d=$ $0.86)$ and clothing products $\left(\mathrm{OXT}^{\mathrm{IN}}, 53 \%\right.$; $\mathrm{PLC}^{\mathrm{IN}}, 23 \% ; t_{(46)}=$ $3.14, p<0.01, d=0.93$ ) chosen by the participants were sustainable. In addition, $\mathrm{OXT}^{\mathrm{IN}}$ nearly doubled the amount of money participants were willing to pay for food products $\left(\mathrm{OXT}^{\mathrm{IN}}\right.$ : $€ 10.26 \pm 5.99 ;$ PLC $^{\mathrm{IN}}: € 6.01 \pm 5.70 ; t_{(46)}=2.52, p=0.02, d=$ 0.74 ) and more than doubled the amount of money devoted to clothing products $\left(\mathrm{OXT}^{\mathrm{IN}}: € 162.31 \pm 154.06 ; \mathrm{PLC}^{\mathrm{IN}}: € 64.67 \pm\right.$ 92.61; $\left.t_{(37.70)}=2.66, p=0.01, d=0.78\right)$ that were framed as socially sustainable. Treatment with $\mathrm{OXT}^{\mathrm{IN}}$ had no such effects in the ecological frame (all $p$ values $>0.05$; Fig. $2 A, B$ ).

In an additional exploratory analysis, we mediandichotomized the sample with respect to childhood trauma experiences and autistic-like traits. However, when we separately included these variables in the repeated-measure ANOVAs with
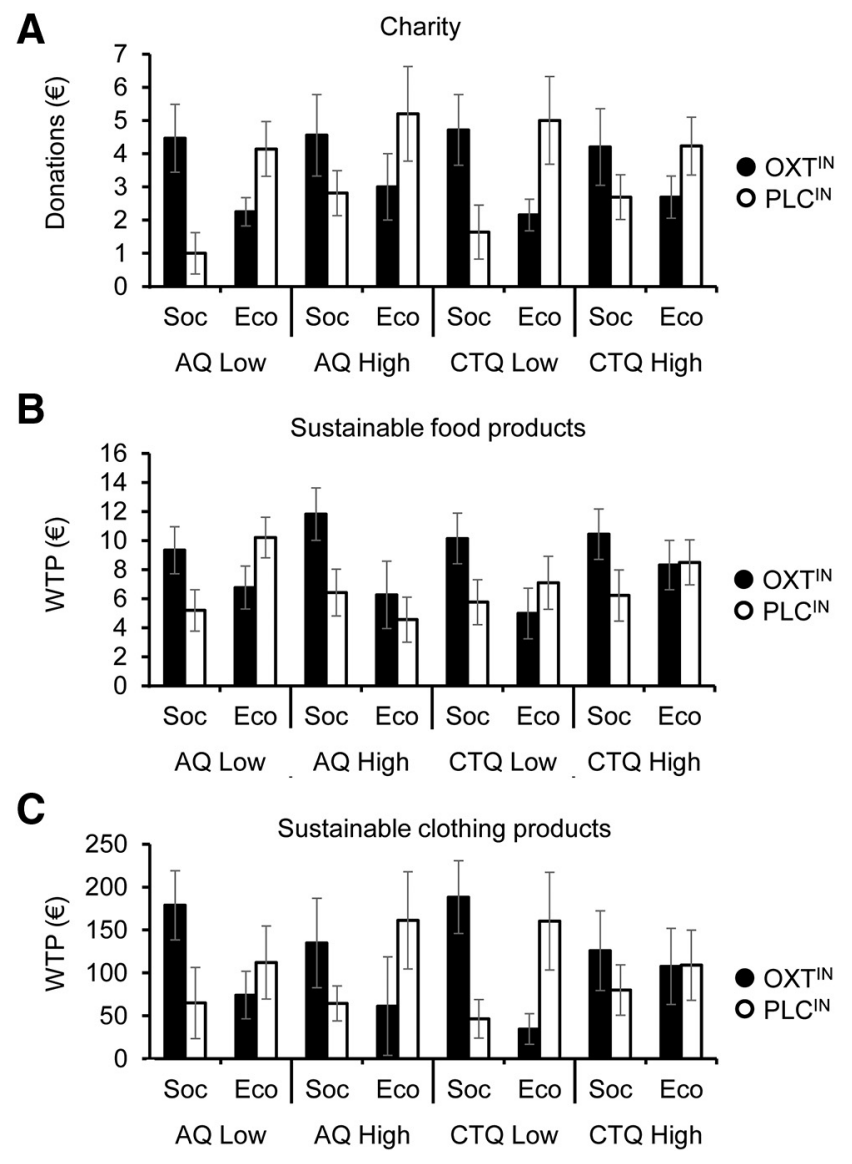

Figure 3. Absence of potential associations with childhood trauma history and autisticlike traits. A median dichotomization yielded groups scoring low versus high on the Autism Spectrum Quotient (AQ) and Childhood Trauma Questionnaire (CTQ). Regardless of these scores, OXT ${ }^{\mathrm{IN}}$ increased donations to the charity $(\boldsymbol{A})$ as well as the amount of money participants were willing to pay for sustainable food products $(\boldsymbol{B})$ and clothing products $(C)$ in the social frame (Soc), but not in the ecological frame (Eco). WTP, willingness to pay.

the between-subject factors "treatment" and "social frame" and the dependent variables "donations," "number of decisions," and "willingness to pay," we observed no further interactions (all $p$ values $>0.05$; Fig. 3). Furthermore, we found that neither the participants in Experiment 1 nor the participants in Experiment 2 cheated when indicating their donation.

\section{Discussion}

Collectively, our findings provide converging evidence that altruistic priorities vary as a function of OXT system activity, with heightened OXT concentrations, either due to exogenous delivery of the peptide (Striepens et al., 2013) or elevated endogenous release, inducing a social altruism bias. This pro-social tendency transcends to the domain of sustainable consumption by making participants willing to pay double the price for goods that are socially sustainable.

Our data are consistent with, and extend, recent observations based on the "intergenerational goods game" that in democratically organized groups of five individuals, intense social interaction, which may enhance endogenous OXT release and thereby produce effects similar to those of exogenously administered OXT $^{\mathrm{IN}}$ (Kis et al., 2013), promotes sustainable decision-making (Hauser et al., 2014). Furthermore, our results are in line with recent reports to the U.S. 
Congress on the nonprofit and charitable sector, documenting that pro-social charities are recipients of larger donations and gifts (Sherlok and Gravelle, 2009).

From a mechanistic perspective, the observed effects of OXT in our study could be mediated by enhanced social awareness (Bartz et al., 2011), which is in accordance with the widely accepted modulatory role of OXT in the psychological domains of empathy, trust, and cooperation (Kosfeld et al., 2005; Domes et al., 2007; Hurlemann et al., 2010). An isolated nonspecific enhancement of trust in charities or "green" companies (Kosfeld et al., 2005), though, would have been evident across both experimental frames and cannot explain why we observed decreased pro-environmental donations following $\mathrm{OXT}^{\mathrm{IN}}$ treatment. This effective shift of donation allocation toward social causes, we suggest, can be interpreted as a specific effect of OXT on pro-social neural underpinnings during economic decision-making and not on economic rationality overall.

Although both of our experiments provided participants with the opportunity to cheat (Barkan et al., 1998; Gino et al., 2009), we found no discrepancies between self-reported and actual donations, suggesting that both the social and ecological frames could perhaps trigger a bias toward ethical behavior even in the most selfish participants, regardless of treatment. In line with previous research, we assume a link between social and ecological responsibility on the one hand and ethical propensities on the other (Mazar et al., 2008; Arrow and Levin, 2009). It remains to be shown by future studies whether priming toward social and ecological responsibility serves as a moral reminder leading individuals to behave more ethically by cheating less (Gino and Mogilner, 2014).

Consistent with current concepts of a context-dependent variation of OXT effects on behavior (De Dreu et al., 2010; Bartz et al., 2011; Scheele et al., 2014), OXT $^{\mathrm{IN}}$ treatment was associated with increased donations in the social frame and decreased donations in the ecological frame. Thus, an OXTinduced social altruism bias is costly, as it reduces a propensity toward ecological responsibility under PLC ${ }^{\mathrm{IN}}$ and low endogenous OXT concentrations.

In previous studies as well as in the present one, social and ecological responsibilities have been experimentally framed without alluding to their potential interconnectedness (Kortenkamp and Moore, 2001). Given that no consensus has emerged regarding the precise relationship between the social and ecological dimensions (Ostrom, 2009), it remains to be investigated in future studies whether or not social and ecological responsibilities represent orthogonal constructs.

By emphasizing that conditions of heightened OXT system activity induce a context-dependent shift in altruistic priorities away from ecological to social responsibility, our findings may have fundamental implications for policy interventions and business strategies designed to sustain ecological resources. There is substantial evidence suggesting physiologically elevated endogenous OXT release in significant percentages of the population, including people engaged in romantic relationships (Schneiderman et al., 2012; Hurlemann and Scheele, 2015), parental care of infants (Rilling and Young, 2014), or social group activities (De Dreu and Kret, 2015). We therefore conclude that using message frames informed by a more accurate understanding of altruism and its underlying regulatory mechanisms, including OXT, institutions, nongovernmental organizations, and companies, may motivate more individuals and groups to sacrifice money for ecological sustainability, which may help improve climate change prevention and the preservation of biodiversity.

\section{References}

Arrow KJ, Levin SA (2009) Intergenerational resource transfers with random offspring numbers. Proc Natl Acad Sci US A 106:13702-13706. CrossRef Medline

Barkan R, Zohar D, Erev I (1998) Accidents and decision making under uncertainty: a comparison of four models. Organ Behav Hum Decis Process 74:118-144. CrossRef Medline

Baron-Cohen S, Wheelwright S, Skinner R, Martin J, Clubley E (2001) The autism-spectrum quotient (AQ): evidence from Asperger syndrome/ high-functioning autism, males and females, scientists and mathematicians. J Autism Dev Disord 31:5-17. CrossRef Medline

Barraza JA, McCullough ME, Ahmadi S, Zak PJ (2011) Oxytocin infusion increases charitable donations regardless of monetary resources. Horm Behav 60:148-151. CrossRef Medline

Bartz JA, Zaki J, Bolger N, Ochsner KN (2011) Social effects of oxytocin in humans: context and person matter. Trends Cogn Sci 15:301-309. CrossRef Medline

Beck AT, Erbaugh J, Ward CH, Mock J, Mendelsohn M (1961) An inventory for measuring depression. Arch Gen Psychiat 4:561-571. Medline

Bernstein DP, Fink L (1998) Childhood trauma questionnaire: a retrospective self-report. San Antonio, TX: Harcourt Brace and Co.

Bock O, Baetge I, Nicklisch A (2014) hroot: Hamburg Registration and Organization Online Tool. Eur Econ Rev 71:117-120.

Cardoso C, Ellenbogen MA, Linnen AM (2012) Acute intranasal oxytocin improves positive self-perceptions of personality. Psychopharmacology 220:741-749. CrossRef Medline

Declerck CH, Boone C, Kiyonari T (2014) The effect of oxytocin on cooperation in a prisoner's dilemma depends on the social context and a person's social value orientation. Soc Cogn Affect Neurosci 9:802-809. CrossRef Medline

De Dreu CK, Kret ME (2015) Oxytocin conditions intergroup relations through upregulated in-group empathy, cooperation, conformity, and defense. Biol Psychiatry. Advance online publication. Retrieved August 3, 2015. doi: 10.1016/j.biopsych.2015.03.020. Medline

De Dreu CK, Greer LL, Handgraaf MJ, Shalvi S, Van Kleef GA, Baas M, Ten Velden FS, Van Dijk E, Feith SW (2010) The neuropeptide oxytocin regulates parochial altruism in intergroup conflict among humans. Science 328:1408-1411. CrossRef Medline

Domes G, Heinrichs M, Michel A, Berger C, Herpertz SC (2007) Oxytocin improves "mind-reading" in humans. Biol Psychiatry 61:731-733. CrossRef Medline

Evans L, Maio GR, Corner A, Hodgetts CJ, Ahmed S, Hahn U (2013) Selfinterest and pro-environmental behaviour. Nat Clim Chang 3:122-125.

Gino F, Mogilner C (2014) Time, money, and morality. Psychol Sci 25: 414-421. CrossRef Medline

Gino F, Ayal S, Ariely D (2009) Contagion and differentiation in unethical behavior: the effect of one bad apple on the barrel. Psychol Sci 20: 393-398. CrossRef Medline

Gino F, Norton MI, Ariely D (2010) The counterfeit self: the deceptive costs of faking it. Psychol Sci 21:712-720. CrossRef Medline

Hauser OP, Rand DG, Peysakhovich A, Nowak MA (2014) Cooperating with the future. Nature 511:220-223. CrossRef Medline

Huffmeijer R, Alink LR, Tops M, Bakermans-Kranenburg MJ, van IJzendoorn MH (2012) Asymmetric frontal brain activity and parental rejection predict altruistic behavior: moderation of oxytocin effects. Cogn Affect Behav Neurosci 12:382-392. CrossRef Medline

Hurlemann R, Scheele D (2015) Dissecting the role of oxytocin in the formation and loss of social relationships. Biol Psychiatry. Advance online publication. Retrieved August 20, 2015. doi: 10.1016/j. biopsych.2015.05.013. Medline

Hurlemann R, Patin A, Onur OA, Cohen MX, Baumgartner T, Metzler S, Dziobek I, Gallinat J, Wagner M, Maier W, Kendrick KM (2010) Oxytocin enhances amygdala-dependent, socially reinforced learning and emotional empathy in humans. J Neurosci 30:4999-5007. CrossRef Medline

Kis A, Kemerle K, Hernádi A, Topál J (2013) Oxytocin and social pretreatment have similar effects on processing of negative emotional faces in healthy adult males. Front Psychol 4:532. CrossRef Medline

Kortenkamp KV, Moore CF (2001) Ecocentrism and anthropocentrism: 
moral reasoning about ecological commons dilemmas. J Environ Psychol 21:261-272. CrossRef

Kosfeld M, Heinrichs M, Zak PJ, Fischbacher U, Fehr E (2005) Oxytocin increases trust in humans. Nature 435:673-676. CrossRef Medline

Mazar N, Amir O, Ariely D (2008) The dishonesty of honest people: a theory of self-concept maintenance. J Marketing Res 45:633-644. CrossRef

National Geographic (2014) Greendex 2014: consumer choice and the environment-a worldwide tracking survey. Retrieved from http://environment.nationalgeographic.com/environment/greendex/.

Nowak MA, Sigmund K (2005) Evolution of indirect reciprocity. Nature 437:1291-1298. CrossRef Medline

Ostrom E (2009) A general framework for analyzing sustainability of socialecological systems. Science 325:419-422. CrossRef Medline

Rilling JK, Young LJ (2014) The biology of mammalian parenting and its effect on offspring social development. Science 345:771-776. CrossRef Medline

Rilling JK, DeMarco AC, Hackett PD, Thompson R, Ditzen B, Patel R, Pagnoni G (2012) Effects of intranasal oxytocin and vasopressin on cooperative behavior and associated brain activity in men. Psychoneuroendocrinology 37:447-461. CrossRef Medline

Rushton JP, Chrisjohn RD, Fekken GC (1981) The Altruistic Personality and the Self-Report Altruism Scale. Pers Indiv Differ 2:293-302. CrossRef

Scheele D, Kendrick KM, Khouri C, Kretzer E, Schlapfer TE, Stoffel-Wagner B, Güntürkün O, Maier W, Hurlemann R (2014) An oxytocin-induced facilitation of neural and emotional responses to social touch correlates inversely with autism traits. Neuropsychopharmacology 39:2078-2085. CrossRef Medline

Schneiderman I, Zagoory-Sharon O, Leckman JF, Feldman R (2012) Oxytocin during the initial stages of romantic attachment: relations to couples' interactive reciprocity. Psychoneuroendocrinology 37:1277-1285. CrossRef Medline

Sheehan DV, Lecrubier Y, Sheehan KH, Amorim P, Janavs J, Weiller E, Hergueta T, Baker R, Dunbar GC (1998) The Mini-International Neuropsychiatric Interview (M.I.N.I.): the development and validation of a structured diagnostic psychiatric interview for DSM-IV and ICD-10. J Clin Psychiatry 59 Suppl 20:22-33; quiz 34-57. Medline

Sherlok MF, Gravelle JG (2009) An overview of the nonprofit and charitable Sector. Retrieved from https://www.fas.org/sgp/crs/misc/R40919.pdf.

Spielberger CD (1984) State-trait anxiety inventory: a comprehensive bibliography. Palo Alto, CA: Consulting Psychologists.

Striepens N, Kendrick KM, Hanking V, Landgraf R, Wüllner U, Maier W, Hurlemann R (2013) Elevated cerebrospinal fluid and blood concentrations of oxytocin following its intranasal administration in humans. Sci Rep 3:3440. CrossRef Medline

Thompson SCG, Barton MA (1994) Ecocentric and anthropocentric attitudes toward the environment. J Environ Psychol 14:149-157. CrossRef

World Commission on Environment and Development (1987) Our common future. Oxford: Oxford UP. 